\title{
Ground support strategy for optimisation of time schedule, Oyu Tolgoi Underground Mine
}

\author{
B Batkhuu Oyu Tolgoi, Rio Tinto Copper and Diamonds, Mongolia \\ LA Johnson Oyu Tolgoi, Rio Tinto Copper and Diamonds, Mongolia
}

\begin{abstract}
Oyu Tolgoi is an underground block cave in the initial development stage, where rapid development, yet comprehensive, ground support is required to begin undercutting and start production. High variability in the rock mass, high stress and deep mining requires various ground support standards and sequences to provide initial stability during development and long-term stability for the production stage.

Different strategies were developed for ground support and reinforcement that support short-term and long-term stability at the appropriate time, to optimise the development rates and reduce rework. The different approaches considered the excavation ground conditions and size, the different short-and long-term purposes of drives, and the future interactions with other excavations and the undercutting.

Management of the strategies required implementation of new or modified data management systems, such as Deswik ${ }^{\circledR}$ and CaveCAD, to collate data acquired from face mapping, drive scanning, and scheduling into a system that could be easily monitored and rapidly modified when required. Strategies were planned into the monthly and weekly schedules using Deswik ${ }^{\circledR}$ for initial and remaining ground support. Remaining ground support maps with attributes of support elements assisted short-and mid-term planning for scheduling ground support remaining against the design. Face mapping, overbreak, and support damage levels were monitored as trigger points to ensure that the appropriate level of ground support was installed at the required time, changing the strategy when required through daily reviews.

The management of geotechnical data and the implementation of ground support strategies have optimised the mining cycles while ensuring that the ground was supported appropriately at the required time. The strategies have increased development and support rates, improving schedule compliance.
\end{abstract}

Keywords: ground support strategy, trigger points, secondary ground support

\section{Introduction}

Oyu Tolgoi underground mine is a large block caving mine in the development stage. The projected extraction horizon of orebody is approximately $2,000 \mathrm{~m}$ long and $280 \mathrm{~m}$ wide, with an average of $360 \mathrm{~m}$ high draw columns. The depth of the extraction horizon below the surface will be 1,300 $\mathrm{m}$ (Oyu Tolgoi LLC 2016). The mine design method is a block cave with big ' $W$ ' undercutting, which consists of a couple of hundred kilometres of lateral development. Ground support design, that aims to provide final long-term stability of tunnel, both in and out of footprint, is one of the most important factors of mine operation. Ground support strategy is optimised for an assortment and arrangement of either primary and secondary support which attempt to support an increased development rate without changing the risk profile to stability, changing designed ground support elements and reducing as much rework as possible. Four types of ground support strategies are recommended based on estimated ground condition, quality control of drill/blast technique and data acquisition of initial and remained ground support for development plan. 


\section{Ground support strategies for optimisation}

Ground support optimisation strategies considered how to reduce the time of the ground support in mining cycle without changing the stability risk profile, ground support designs or need for additional rework. As shown in Figure 1, the ground support strategy incorporates the key elements of ground conditions based on the modified rock mass rating (MRMR) (Laubscher \& Jakubec 2001) and stress regime (ON-Footprint: high abutment stress and cave loading or OFF-Footprint: normal-stress regime) (Kaiser et al. 2000). The ground support strategies are applicable for development under a $6.5 \mathrm{~m}$ wide span and were not applied to large excavations or chambers.

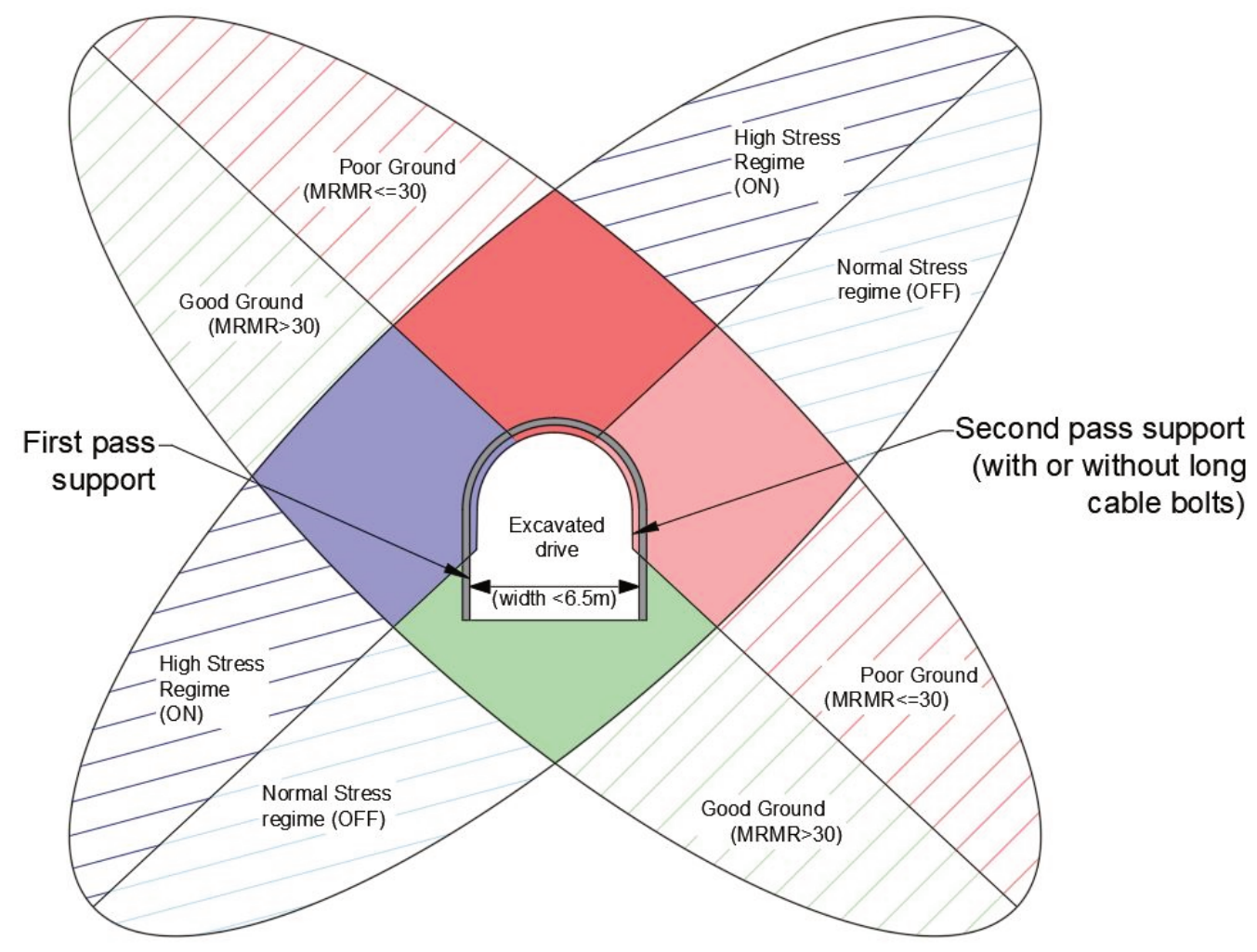

\section{Figure 1 Specifications of ground support strategy category}

Final ground support design would be divided into a two-pass installation sequence of primary (first pass) and secondary (second pass) support. Primary ground support is provisional support for short-term stability (prior to caving stress influence) until the secondary ground support is installed.

Primary support is installed during or immediately after excavation to ensure safe working conditions during subsequent excavation and to initiate the process of mobilising and preserving rock mass strength by controlling boundary displacements. Any additional support or reinforcement installed thereafter is termed second pass (secondary) support. Second pass support is typically in the form of strapping, cable bolting, and/or the application of additional shotcrete. Second pass support is designed to handle high induced stresses and stress changes resulting from mining activities. A summary of the key primary and secondary support activities is summarised as follows:

1. Primary (first pass) support: Rockbolts and mesh are installed systematically after shotcrete applied on the rock surface.

2. Secondary (second pass) support: Remaining mesh and/or strapping, cable bolting as-designed and additional layer of shotcrete.

Four types of ground support strategy (Table 1) are designed based on the function of tunnel and rock mass condition. 
Table 1 Description of ground support strategy

Rescription
papid enabler (RE) - drives to enable a service or function, service
campaign second pass ground support in long sections with little
impact to other mining activities.
Two options are recommended:
RE 1 - sidewall surface ground support (mesh and second layer of
shotcrete) and cable bolts are deferred by ground support strategy
in development stage, then installed as services are removed.
RE 2 - all first pass surface ground supports as-designed would be
installed in-cycle, based on planning or ground conditions.

\section{Data acquisition techniques to support ground support strategies}

The main data acquisition techniques are face mapping, rock mass assessment, drive profile scanning, and ground support damage monitoring which determine the ground support strategy and provide the trigger points for changes to the ground support strategy.

\section{1 $\quad$ Face mapping}

Every blasted heading is mapped to collect rock mass properties, fracture frequency, discontinuity condition, major structures, weakness zones, and lithology to perform rock mass classification. Facemapper, a Rio Tinto software developed in-house, is an application developed to collect geotechnical data electronically in the field, calculate classifications (including MRMR), and sync data to the CaveCAD database directly for storage and reference (Savage et al. 2016). 


\subsection{Development heading scanning}

Both face mapping and laser scanning ( $Z+F$ imaginer) would be conducted simultaneously to minimise inspection time. 3D laser scanning shows actual profiles of blasted heading which are compared with the tunnel design profile and drill surveys to calculate the overbreak percentage and increased span size of excavations. Features (polygon) which are created by the laser scan processing include a drive name with chainage, advance length and final ground support design.

\subsection{Damage mapping}

Any sign of deterioration and loading of ground support and reinforcement would be observed and the location recorded on the damage mapping application that syncs with the CaveCAD database. Assessments on the level of damage and changes on ground support elements are conducted and reviewed for changing the ground support strategy if required.

\section{$4 \quad$ Data management systems to support ground support strategies}

Data management systems are used to implement ground support strategy, both in execution of mine planning and ground control aspect. Data of rock mass characterisation, ground support and geotechnical monitoring is stored in the CaveCAD database by its location (Savage et al. 2016). Deswik ${ }^{\circledR}$ and web-based data visualisation tools use this information to help illustrate and analyse geotechnical data with the input from mine designs and schedules.

\subsection{CaveCAD}

CaveCAD is the central repository for captured geotechnical data at Oyu Tolgoi (Savage et al. 2018, p. 2). The CaveCAD system was developed by Rio Tinto for the purpose of ensuring secure and robust management of geotechnical data during both the development and production phases of an underground mine. It is an integrated geotechnical data management system, capturing a range of production data, geotechnical monitoring data, geotechnical mapping, and ground support installation quality data (Savage et al. 2016, p. 769). The CaveCAD system has been used in various stages of mining before implementation at Oyu Tolgoi, i.e. Rio Tinto's Argyle Diamond Mine for data capture and storage in a producing block cave mine, and the Rio Tinto Kennecott Copper mine for data capture and storage of underground development. Data is stored in a common database, creating a single coherent system that all authorised users can access. CaveCAD includes automatic data importing, remote (offline) data collection through tablet applications, and scheduled or ad hoc reporting of processed and analysed data.

\subsection{Deswik ${ }^{\circledR}$}

Mine Planning teams use ground support strategy and remaining ground support quantity to estimate development rate, and ground support installation duration respectively. The ground support strategy enables numerous benefits for both planning and operation teams:

- Maximise the development rate of critical headings.

- Maximise equipment productivity with campaign installation of cable bolt support.

- Utilise equipment to install critical ground support instead of doing ad hoc ground support everywhere.

- Postpone non-essential ground support until commissioning of additional equipment.

- Simplified first pass and second pass ground support plans to reduce confusion associated with different types of second pass ground support consumables and activities.

Developing multiple headings with rapid strategy could create a large amount of ground support backlog and cause low equipment utilisation. Therefore, ground support backlog needs to be monitored during the 
planning process. The remaining ground support database are updated in Deswik ${ }^{\circledast}$.CAD and Deswik ${ }^{\circledast} . M D M$ on a weekly basis based on visual inspections and daily reports.

To estimate the date of the cave initiation and the start of production, additional ground support tasks are included in the schedule file based on the most updated information.

Deswik $^{\circledast}$, via the CaveCAD database, is used as the ground support mapping tool and includes the following key elements:

1. Data collected through laser scanning of each heading after blasting.

2. Scan data is geo-referenced and processed to provide excavation compliance to design, advance length, chainage and assigned name.

3. As-built files are prepared in Deswik ${ }^{\circledast}$ for each heading.

4. Attributes of the remaining ground support as per the ground support strategy in Deswik ${ }^{\circledR}$.

5. Calculate and summarise the remaining ground support as shown in Figures 2 and 3.

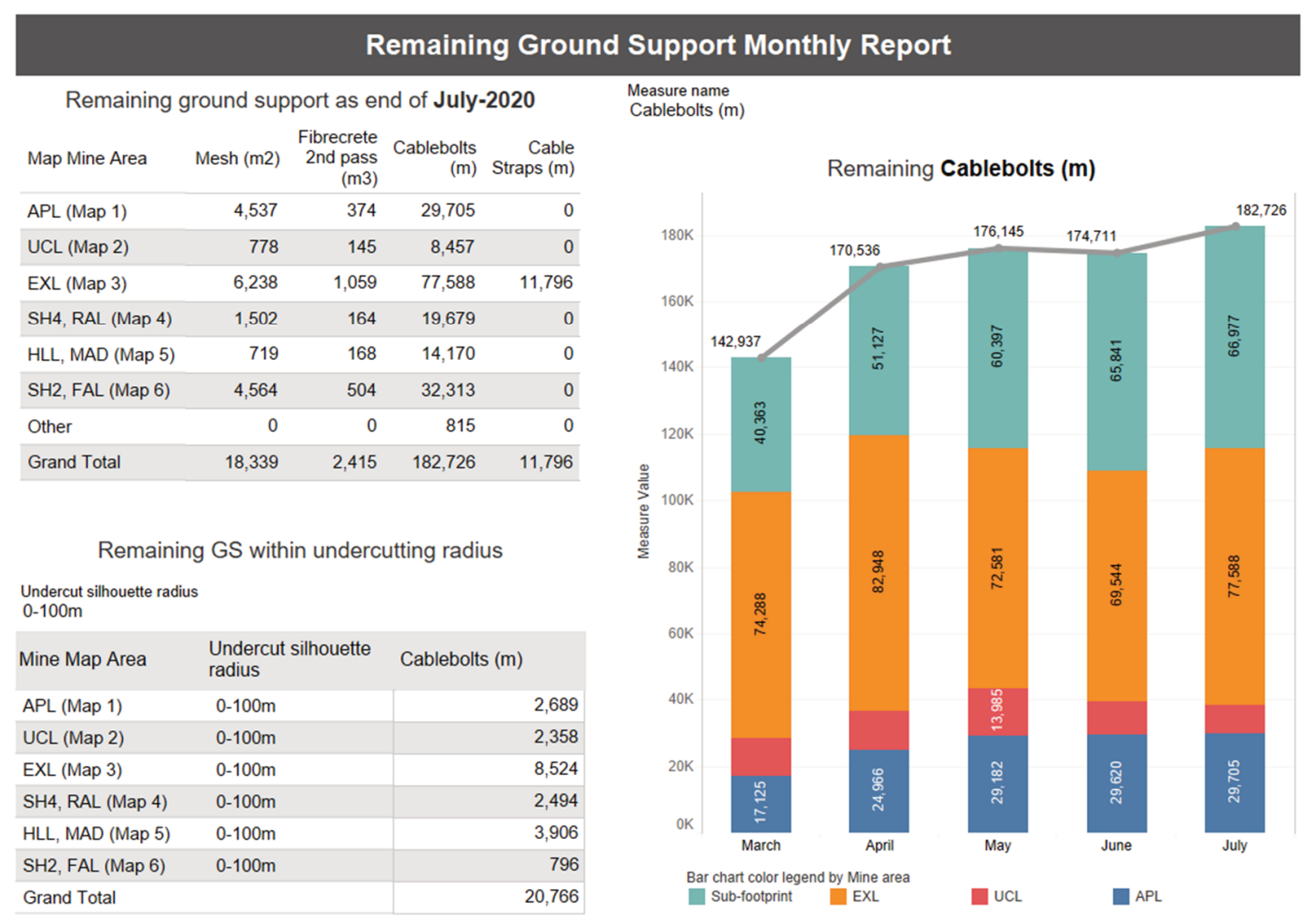

Figure 2 Plot view of remaining ground support 


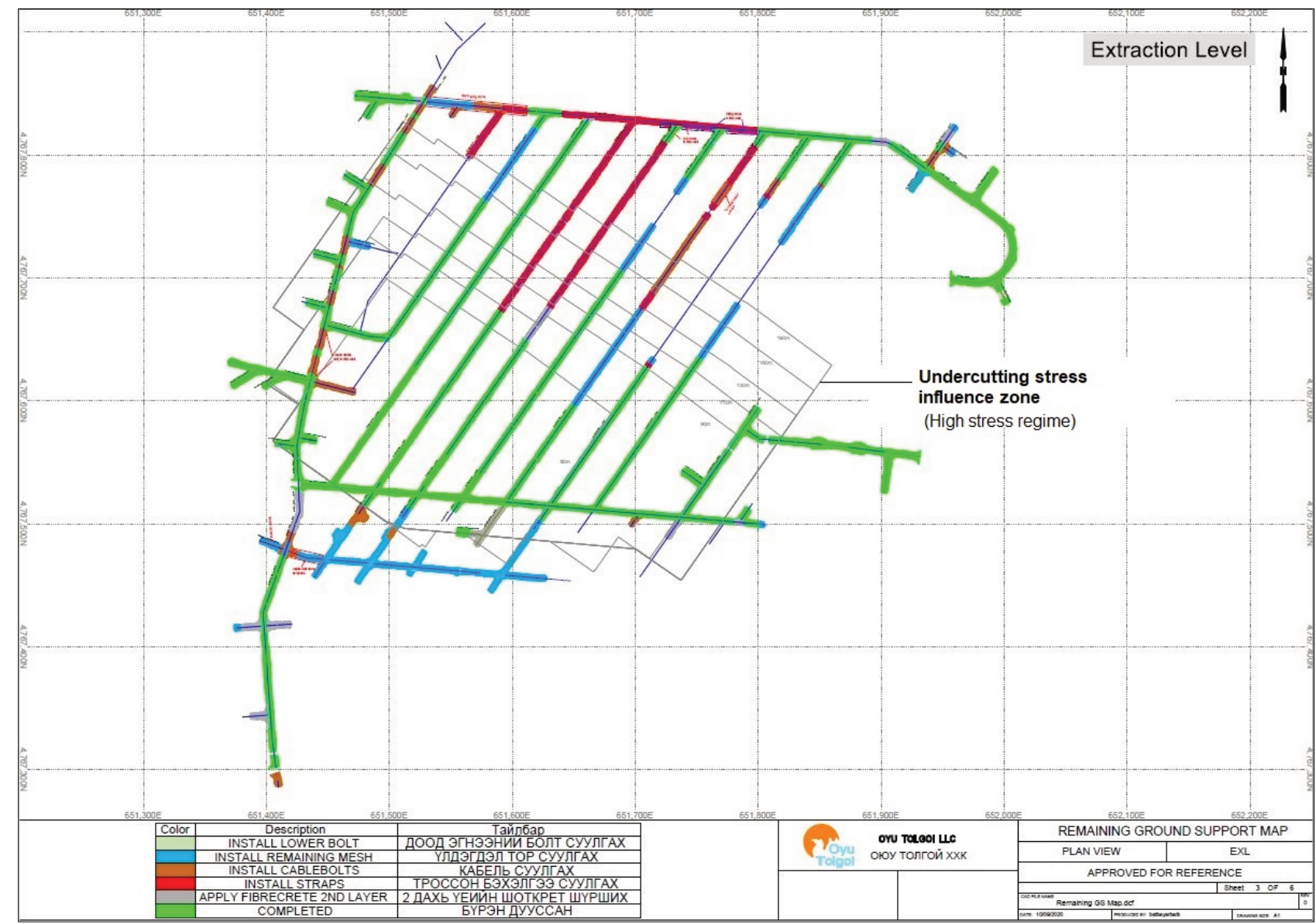

Figure 3 Example plot view of remaining ground support map (OTUG-Extraction level)

\section{$5 \quad$ Implementation of ground support strategies}

Ground support is one of the critical activities for high rate lateral development in deep underground mines such as Oyu Tolgoi. Ground support strategies are intended to optimise and schedule ground support work with the application of data collected. Ground conditions at Oyu Tolgoi underground can be challenging and variable, and geotechnical conditions are periodically updated by field observation and monitoring. This allows for more flexible short- and mid-term mine planning and ground support installation to achieve long-term mine development optimisation. Daily geotechnical data collection and monitoring systems are effective tools for presenting the data and escalating concerns to different user levels of up-to-date data from centralised data management systems such as Deswik $^{\circledR}$ and CaveCAD.

\subsection{Scheduling of ground support strategies and remaining ground support elements}

The mid- and short-term mining plan indicates the ground support strategy based on the required mining cycle time, function of the drive, and ground conditions as shown Figure 4. The remaining ground support is scheduled to optimise equipment utilisation of availability and reduce tramming and set up times. 


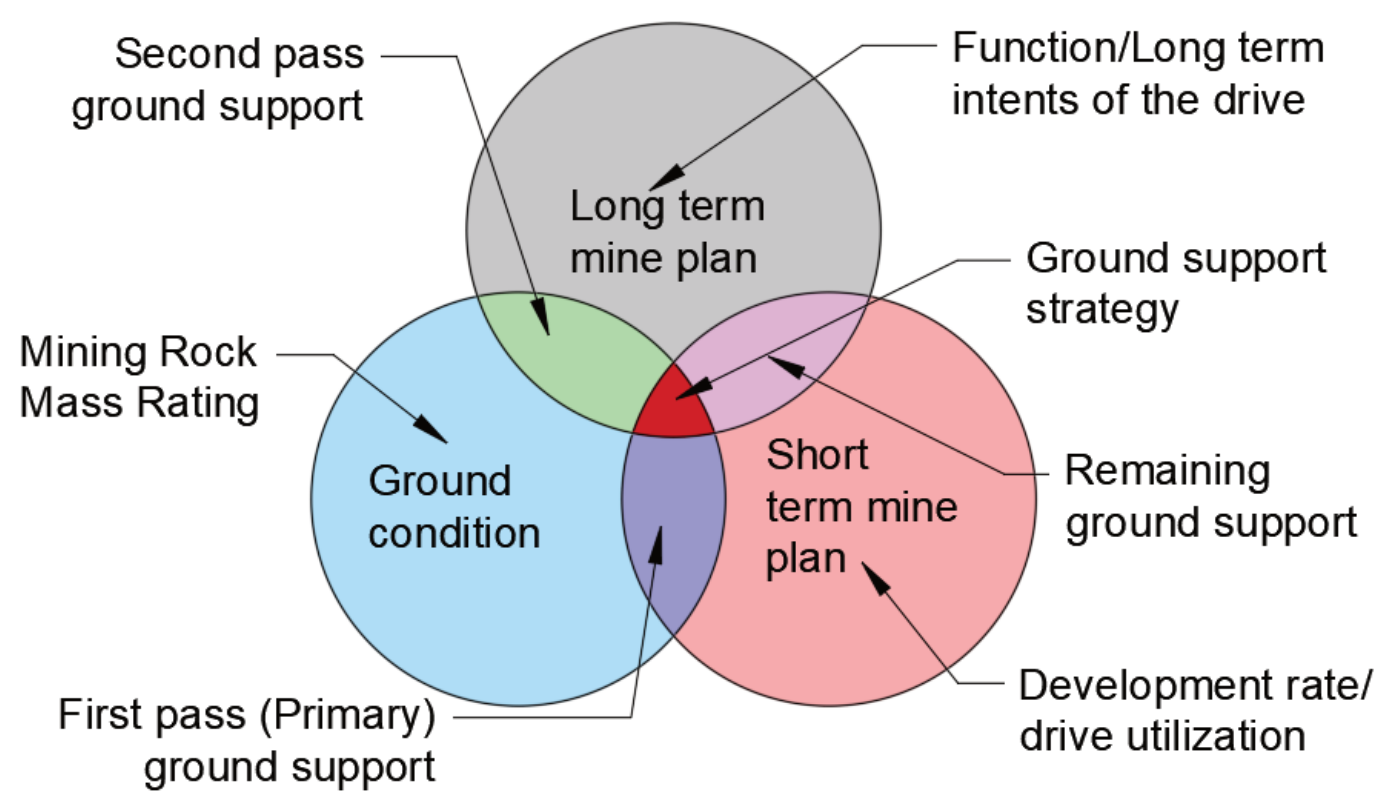

Figure 4 Inputs of the ground support strategy

The remaining ground support map includes an amount of designed and actual ground support elements installed for every development round. The maps are updated weekly based on the geotechnical first pass ground support inspection and the jumbo performance report from the Pitram database.

\subsection{Monitoring appropriateness of ground support strategies}

Ground support strategy is based on the expected (modelled) geotechnical condition and mine plan of the development stage. The geotechnical monitoring program is key for controlling the appropriateness of ground support strategy. One initial and viable approach to control ground support sequence is a daily QA/QC meeting with the mining team which must consider the following geotechnical assessments:

- Ground condition, evaluated by MRMR or in situ rock mass rating which is calculated on FaceMapper.

- Actual excavation quality control, over or underbreak, increased span size measured with 3D scanner data.

- Ground support QA/QC.

- Ground support damage level or convergence rate as indicated in Figure 5.

Besides geotechnical inspections and measurements to monitor the ground support strategy, other feedback and observations can be useful to schedule geotechnical inspections and validate data such as rock noise reporting, visual damage of surface support, and equipment appropriateness to install ground support. Drive purpose, including permanent services installation, must also be considered to prevent rework with services and infrastructure.

Outcomes of the QA/QC meeting will be blasting technique and round length of advance based on rock mass rating and any tunnel stability issues which require a re-assessment of the ground support strategy. The ground support strategy would be assessed based on the triggers outlined in Table 2 . 


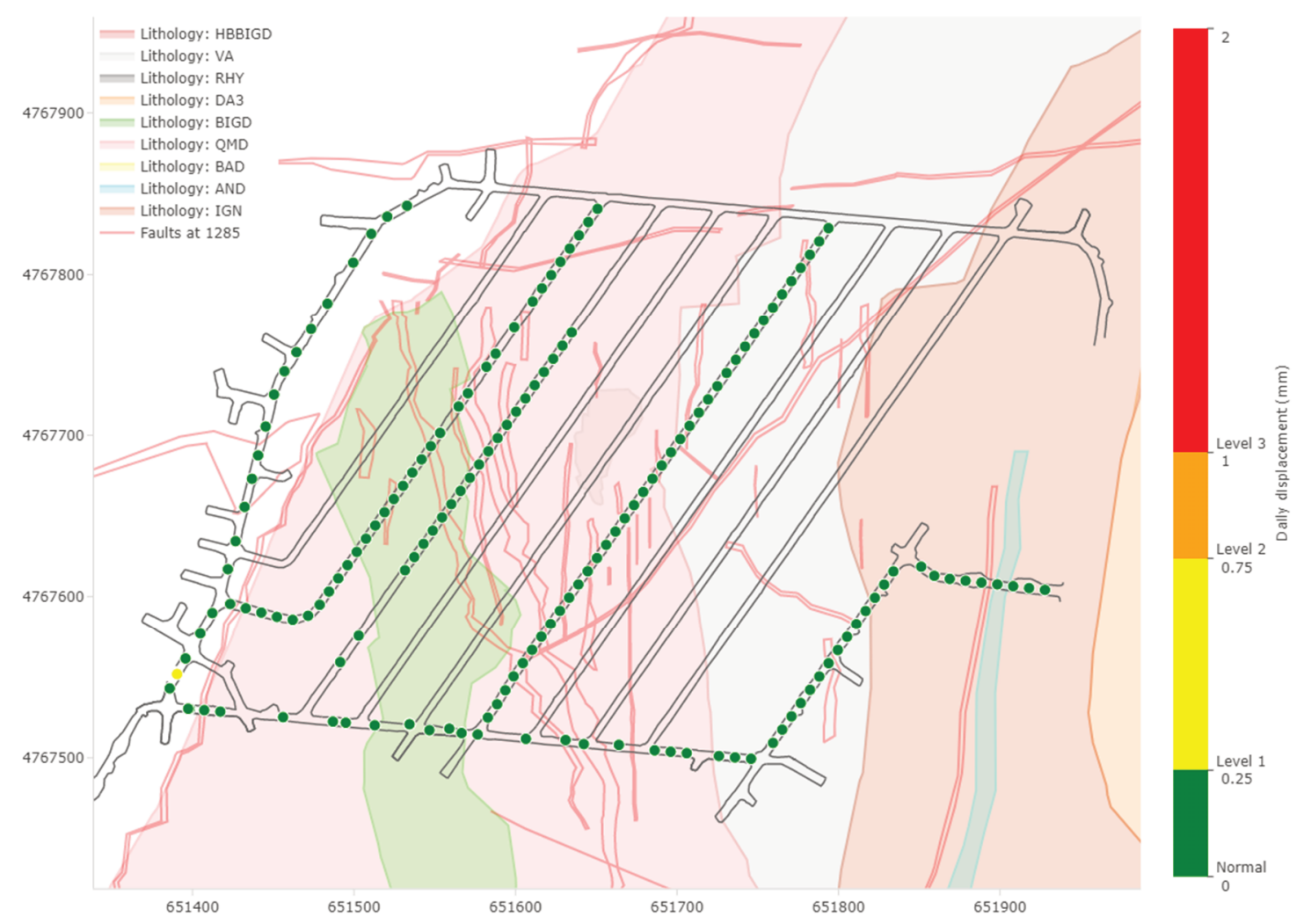

\section{Figure 5 Plot view of convergence pins}

\subsection{Triggers and changes to ground support strategies}

Each geotechnical assessment has a trigger value to change or optimise the ground support strategy in Oyu Tolgoi underground as summarised in Table 2.

Table 2 Triggers and changes to ground support strategy

\begin{tabular}{|c|c|c|c|}
\hline No. & Geotechnical triggers & Trigger points & Ground support strategy changes \\
\hline \multirow[t]{2}{*}{1} & \multirow{2}{*}{$\begin{array}{l}\text { Ground condition } \\
\text { (MRMR) }\end{array}$} & MRMR is $<30$ & \multirow{2}{*}{$\begin{array}{l}\text { Full in-cycle support including } \\
\text { secondary support is installed or } \\
\text { ground support strategy is re- } \\
\text { assessed }\end{array}$} \\
\hline & & Variance of expected rate is $>20$ & \\
\hline \multirow[t]{3}{*}{2} & \multirow[t]{3}{*}{$\begin{array}{l}\text { Excavation quality } \\
\text { (overbreak) }\end{array}$} & $\begin{array}{l}>30 \% \text { overbreak compared to } \\
\text { design solid }\end{array}$ & \multirow[t]{3}{*}{$\begin{array}{l}\text { Full in-cycle support including } \\
\text { secondary support is installed }\end{array}$} \\
\hline & & Excavated drive width is $>6.5 \mathrm{~m}$ & \\
\hline & & $\begin{array}{l}\text { Continuous noticeable (20-30\%) } \\
\text { overbreak in development }\end{array}$ & \\
\hline \multirow[t]{3}{*}{3} & \multirow{3}{*}{$\begin{array}{l}\text { Ground support } \\
\text { damage/convergence }\end{array}$} & Total convergence is $>100 \mathrm{~mm}$ & \multirow[t]{3}{*}{ Rehab plan is to be conducted } \\
\hline & & $\begin{array}{l}\text { Failures on permanent primary } \\
\text { supports (rock or cable bolts) }\end{array}$ & \\
\hline & & Fall of ground & \\
\hline 4 & $\begin{array}{l}\text { Intents of drive } \\
\text { changed }\end{array}$ & Excavation risk rating (ERR) & $\begin{array}{l}\text { Ground support design is reviewed } \\
\text { to meet criteria of ERR }\end{array}$ \\
\hline
\end{tabular}




\section{$6 \quad$ Benefits achieved using ground support strategies}

Benefits of the ground support strategy are tracked on two main activities before and after the ground support strategy was implemented; the development rate of priority headings, and compliance of cable bolting. The increased production rates of the top two priority headings are shown in Figure 6 . Development rates of high priority headings were used for comparison because of the positive impact to the critical path that they provided.

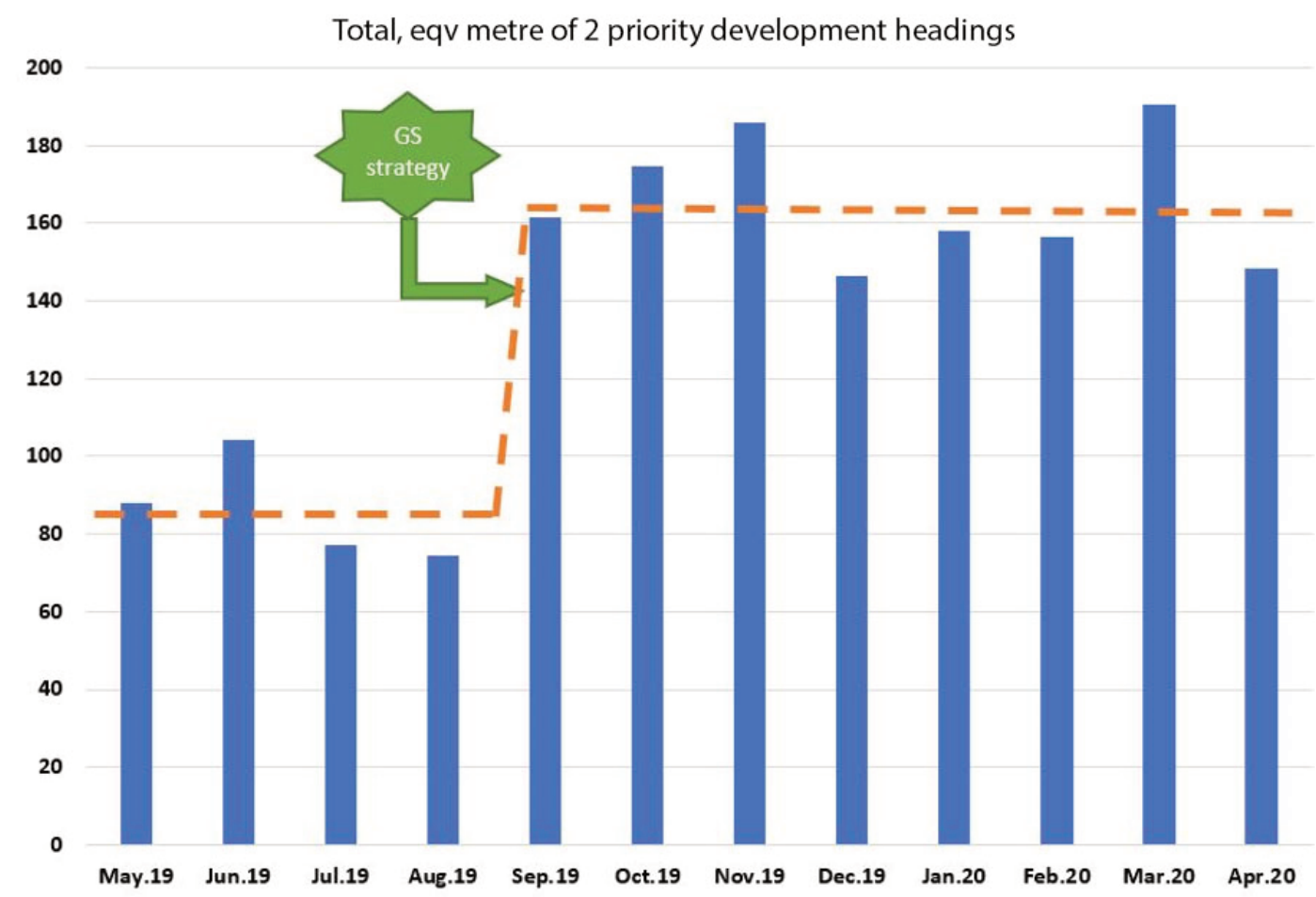

Figure 6 Increased production rates of priority headings where the ground support strategy was applied from September 2019

Productivity of monthly installation of cable bolts by the same equipment was compared for May to July 2019 and May to July 2020, before and after ground support strategy implementation (Figure 7). Cable bolter productivity increased by an average of $40 \%$ due to optimised schedule of ground support with minimised travelling, setting up and standby hours of equipment.

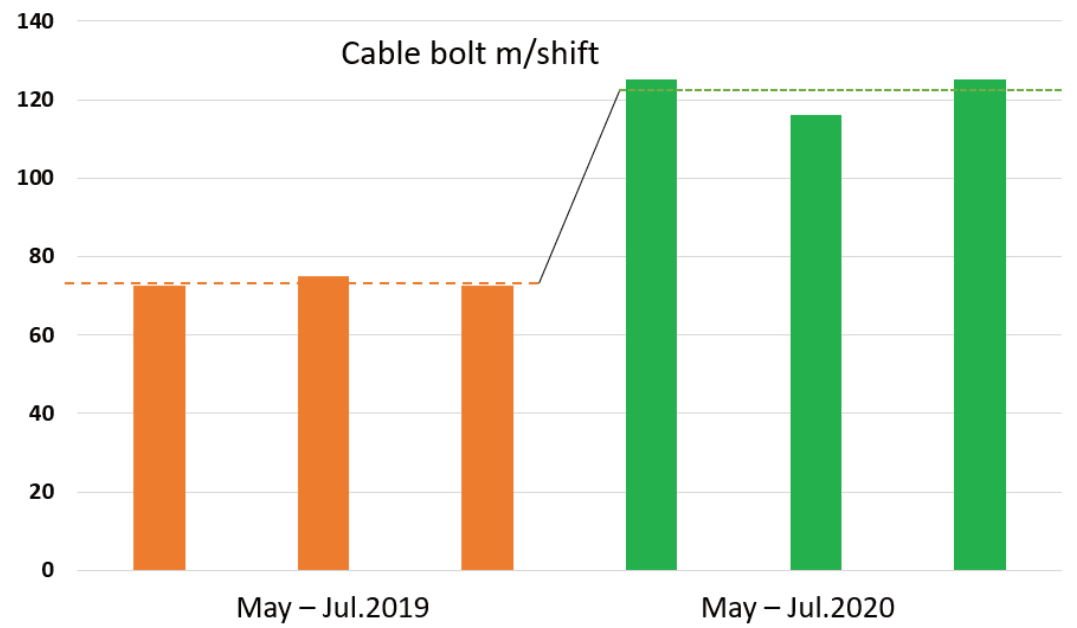

Figure 7 Cable bolter productivity comparison for May to July 2019 and May to July 2020 


\section{Conclusion}

The ground support strategies implemented at Oyu Tolgoi were able to achieve:

1. Up-to-date measurements for planning and time scheduling ground support work by ground support strategy through digital geotechnical data collection systems and databases.

2. Improved mining cycle times based on observational data of performance in ground support, which benefitted short- and mid-term mine planning.

3. The recommended primary support was able to maintain the excavation in a stable conditions, even though high development rates of drives were achieved. Optimal ground support steps and monitoring have increased the understanding of the ground support performance under various geotechnical conditions.

4. Significant production benefits in both mining development rates and ground support installations by the same equipment due to the optimisation of ground support strategies.

5. Geotechnical triggers for the implementation of ground support strategies to immediately respond to stability issues at tunnels.

\section{Acknowledgement}

The authors acknowledge Glenn Watt, Unubold Perlee, Oyunbaatar Batbayar and Odselmaa Dorjsuren for their assistance with internal reviews and comments, and the Oyu Tolgoi Underground Geoscience team and Underground Development Team.

\section{References}

Kaiser, PK, Diederichs, MS, Martin, CD, Sharp, J \& Steiner, W 2000, 'Underground Works in Hard Rock Tunnelling and Mining', Proceedings of the International Conference on Geotechnical and Geological Engineering, Technomic, Chicago, pp. 841-926.

Laubscher, DH \& Jakubec, J 2001, 'The MRMR Rock Mass Classification for Jointed Rock Masses', in WA Hustrulid \& RL Bullock (eds), Underground Mining Methods: Engineering Fundamentals and International Case Studies, Society for Mining, Metallurgy, and Exploration, Inc., Littleton, pp. 475-481.

Oyu Tolgoi LLC 2016, Oyu Tolgoi Underground Feasibility Study, Oyu Tolgoi LLC, Ulaanbaatar.

Savage, E, Talu, S, Sturm, P \& Van As, A 2016, 'Development and implementation of the CaveCAD ground support module for cost and safety improvements in block cave mines', Proceedings of the Seventh International Conference \& Exhibition on Mass Mining, The Australasian Institute of Mining and Metallurgy, Melbourne, pp. 769-772.

Savage, E, Moorcroft, T \& Talu, S 2018, 'Using a structured data management system to improve mine development efficiencies', in Y Potvin \& J Jakubec (eds), Proceedings of the Fourth International Symposium on Block and Sublevel Caving, Australian Centre for Geomechanics, Perth, https://doi.org/10.36487/ACG_rep/1815_61_Moorcroft 